\title{
Drug-Induced Acute Kidney Injury in Diabetes Mellitus
}

\section{Amel Harzallah ${ }^{1,2}$, Hayet Kaaroud1,2, Mariem Hajji, ${ }^{1,2}$, Fethi Ben Hamida ${ }^{2,3}$, K. Khiari, ${ }^{1,2}$, G. Gorsane ${ }^{1,2}$, Taieb Ben Abdallah1,2}

${ }^{1}$ Department of Medicine A, Charles Nicolle Hospital, Tunis, Tunisia

${ }^{2}$ Faculty of Medicine, University of Tunis El Manar, Tunis, Tunisia

${ }^{3}$ Laboratory of Renal Pathology LR00SP01, Charles Nicolle Hospital, Tunis, Tunisia

Email: *amel_harz@yahoo.fr

How to cite this paper: Harzallah, A., Kaaroud, H., Hajji, M., Hamida, F.B., Khiari, K., Gorsane, I. and Abdallah, T.B. (2016) Drug-Induced Acute Kidney Injury in Diabetes Mellitus. Open Journal of Nephrology, 6, 176-187.

http://dx.doi.org/10.4236/ojneph.2016.64023

Received: August 23, 2016

Accepted: December 25, 2016

Published: December 28, 2016

Copyright $\odot 2016$ by authors and Scientific Research Publishing Inc. This work is licensed under the Creative Commons Attribution International License (CC BY 4.0).

http://creativecommons.org/licenses/by/4.0/

\begin{abstract}
Background: Drug-induced acute kidney injury is a common situation in clinical practice. Many treatments are involved and they are even more aggressive when associated with a predisposing factor such as diabetes. We aimed to investigate clinical features of acute drug-induced kidney injury in diabetics in order to clarify renal prognosis. Methods: This was a descriptive and analytical retrospective study including diabetics who presented drug-induced acute kidney injury, conducted in our department during the period from 1986 to 2015. Acute kidney injury was classified according to Kidney Disease Improving Global Outcomes criteria. We analyzed medical records of patients. Results: 31 patients were included with mean age of 65.41 years and gender ratio M/F at 0.93 . Diabetes was type 2 in $97 \%$ of cases. Mean previous creatinine clearance was $39.33 \mathrm{ml} / \mathrm{min} / 1.73 \mathrm{~m}^{2}$. Drugs involved were blockers of renin-angiotensin system (35\%), aminoglycosides (16\%), non-steroidal anti-inflammatory (16\%), diuretics (13\%), lipid-lowering agents (10\%), rifampicin (6\%) and ifosfamide (3\%). Extracellular dehydration was present in nine cases (29\%). Main drug combinations were with diuretics in 16 cases (52\%) and with ACE inhibitor or ARB in eight cases (26\%). Oligo anuria was observed in 5 cases (16\%). Proteinuria with urine strips was objectified in 25 cases (81\%). Acute kidney injury was grade 3 in 24 cases (77\%), grade 2 in three cases (10\%) and grade 1 in four cases (13\%). Renal survival at 102 months was $57 \%$. Identified renal prognosis factors were serum phosphorus $>1.47 \mathrm{mmol} / \mathrm{l}(\mathrm{p}=0.01)$, proteinuria at urine strips $(\mathrm{p}=0.042)$, dehydration $(\mathrm{p}=0.013)$, oral antidiabetic treatment $(\mathrm{p}=0.038)$, intravenous rehydration $(\mathrm{p}=$ $0.021)$ and insulin $(p=0.006)$. Conclusion: Drug-induced acute kidney injury is potentially serious in diabetics. Prevention is essential to improve the prognosis of this renal damage.
\end{abstract}




\section{Keywords}

Renal Failure, Nephrotoxicity, Drugs

\section{Introduction}

Drug-induced acute kidney injury (AKI) is frequent in clinical practice [1]. Indeed, the kidney is an organ particularly vulnerable to drug toxicity in the body by its own functions of filtration, concentration and disposal as well as its rich vascularization [2].

Involved drugs are numerous with multiple mechanisms. Drug nephrotoxicity may be related either to a specific effect of treatment, or to the induction of hypovolemia or by altering intrarenal hemodynamics. Treatments involved are even more aggressive when associated with one or more predisposing factors including diabetics [3].

Drug-induced AKI represents iatrogenic adverse events, mostly preventable, whose prognosis is typically better than other etiologies of AKI. They are potentially serious since they are associated with high morbidity and mortality and the risk of progression to end stage kidney disease (ESKD) [4].

Knowledge of risk factors and mechanisms of drug-induced nephrotoxicity are the basis for improved prevention and also for a better management of these patients [5]. Pre-scription of potentially nephrotoxic drugs should be carried out in compliance with therapeutic indications. It must also take into account drug interactions and field of patients.

Diabetes mellitus is the single largest contributor to the growing prevalence of chronic kidney disease (CKD) worldwide and is one of the major risk factors for development of AKI [6]. Meanwhile, literature is poor about prognostic factors of this condition in diabetic patients.

We conducted an analytic study with the purpose to establish prognostic factors of drug-induced AKI in these patients.

\section{Patients and Methods}

We performed a retrospective data analysis by reviewing the medical records of diabetic patients hospitalized at our department from January 1986 to June 2015 who presented an AKI after taking a drug with a compatible timeline from discovery of the AKI and drug intake.

We excluded individuals who were $\leq 18$ years of age, critically ill patients and those who received iodinated contrast agents.

We collected data on demographics and past medical history, including baseline kidney function, hypertension, coronary artery disease, diabetic neuropathy, diabetic retinopathy and peripheral artery disease.

We noted dose, duration and frequency of administration of offending drug prior to AKI.

We also recorded the use of all other drugs administrated concomitantly with drug in 
question. The clinical and para-clinical data were collected from medical records.

Outcomes included renal recovery, length of hospital stay and mortality.

We defined complete renal recovery by a decrease in serum creatinine with return to baseline creatinine.

Local ethics committee had no objections against this study. Written consent was waived because of the retrospective observational nature of the study.

Glomerular filtration rate was evaluated according to Chronic Kidney Disease Epidemiology Collaboration (CKD-EPI) equation. Stages of CKD were defined according to the International Foundation Kidney disease Improving Global outcomes (KDIGO) [7].

AKI was defined as $26.5 \mu \mathrm{ml} / \mathrm{L}$ or 1.5 -fold increase in creatinine relative to baseline serum creatinine. Severity of AKI was classified on the basis of peak creatinine increment into three stages according to KDIGO criteria [8].

When baseline creatinine was unknown, it was estimated by the CKD-EPI equation assuming a glomerular filtration ratio of $75 \mathrm{ml} / \mathrm{min} / 1.73 \mathrm{~m}^{2}$ as validated by Bagshaw et al. [4] [9].

ESKD has been defined by renal creatinine clearance below to $15 \mathrm{ml} / \mathrm{min}$ requiring maintenance dialysis.

\section{Statistical Analysis}

Statistical analyses were performed using SPSS 19. The results were presented as means \pm SD for continuous variables and percentage for categorical variables.

Differences between groups were evaluated by Chi 2 test for percentages. In case of significance of chi-square test with non validity we used Fisher's bilateral test.

Comparison of independent groups was performed using the Student's $t$ test for independent groups.

A $p$ value less than 0.05 was considered statistically significant.

Quantitative variables were transformed into qualitative variables with two modalities. To determine the threshold at which it must "cut" quantitative variable, we have established ROC (Receiver Operating Characteristics) curve. After verifying that the area under the curve was significantly $>0.500$, we have chosen the threshold value of the variable as corresponding to the best couple "sensitivity-specificity".

A Kaplan-Meier method was used for comparison of survival.

\section{Results}

Among 182 diabetic patients presenting an AKI during the period of the study, we identified 31 cases of drug induced AKI (17\%).

Thirty one patients were then included. The average age of patients was 65.41 years (39 - 79 years). The age was over 65 years in 17 cases (55\%). Gender ratio M/F was 0.93 .

Diabetes was type 2 in 30 cases (97\%). Median duration of diabetes was 165.45 months (2 - 480 months).

Ten patients (32\%) were dependent to insulin therapy and 21 patients (68\%) were on 
oral antidiabetic treatment. Hypertension was present at diagnosis in 25 cases (81\%). Diabetic retinopathy was identified in 15 cases (48\%).

Baseline serum creatinine was available in 28 cases (90\%) with median baseline creatinine at $205.48 \mu \mathrm{mol} / \mathrm{L}(58-453 \mu \mathrm{mol} / \mathrm{L})$ and median creatinine clearance at $39.33 \mathrm{ml} /$ $\mathrm{min} / 1.73 \mathrm{~m}^{2}\left(8.4-92.9 \mathrm{ml} / \mathrm{min} / 1.73 \mathrm{~m}^{2}\right)$. Twenty three patients had a creatinine clearance less than $60 \mathrm{~mL} / \mathrm{min} / 1.73 \mathrm{~m}^{2}$ (74\%). Table 1 summarizes the baseline patient demographics along with clinical and biochemical parameters.

Initial symptoms were vomiting in 11 cases $(35 \%)$ and asthenia with anorexia in 11 cases (35\%).

Table 1. Clinical and biological parameters of patients.

\begin{tabular}{|c|c|c|}
\hline Parameter & Average value & Range \\
\hline Age (years) & 65.41 & $39-79$ \\
\hline BMI $\left(\mathrm{kg} / \mathrm{m}^{2}\right)$ & 27.45 & $19.4-35.7$ \\
\hline SBP (mmHg) & 133.55 & $70-180$ \\
\hline $\mathrm{DBP}(\mathrm{mmHg})$ & 73.87 & $40-100$ \\
\hline Diuresis (ml/24h) & 1033.33 & $0-2000$ \\
\hline Urea $(\mathrm{mmol} / \mathrm{l})$ & 33 & $11-56$ \\
\hline Creatinin $(\mu \mathrm{mol} / \mathrm{l})$ & 631.52 & $157-1158$ \\
\hline Glycemia (mmol/l) & 8.68 & $2.96-23.69$ \\
\hline $\mathrm{Hb}(\mathrm{g} / \mathrm{dl})$ & 9.74 & $7.4-12.4$ \\
\hline WBC & 10237 & $3900-23900$ \\
\hline Platelets & 297166 & $126,000-447,000$ \\
\hline $\mathrm{AR}(\mathrm{mmol} / \mathrm{l})$ & 18.69 & $7.9-29$ \\
\hline Calcemia (mmol/l) & 2.25 & $1.8-2.57$ \\
\hline Phosphatemia (mmol/l) & 1.76 & $0.58-3.88$ \\
\hline ASAT (U/l) & 29.38 & $8-100$ \\
\hline ALAT (U/l) & 23.33 & $6-72$ \\
\hline GGT (U/l) & 34.37 & $13-172$ \\
\hline CPK (U/l) & 377.2 & $19-2970$ \\
\hline $\mathrm{AP}(\mathrm{U} / \mathrm{l})$ & 104.92 & $42-345$ \\
\hline Bilirubin (mg/l) & 19.77 & $4.2-78$ \\
\hline $\mathrm{LDH}(\mathrm{U} / \mathrm{l})$ & 583.1 & $165-2817$ \\
\hline CRP (mg/l) & 17.9 & $0.8-188$ \\
\hline SA & 32.11 & $15.5-45$ \\
\hline 24-hour Proteinuria $(\mathrm{g} / 24 \mathrm{~h})$ & 1.42 & $0-8.8$ \\
\hline
\end{tabular}

BMI: body mass index, SBP: systolic blood pressure, DBP: diastolic blood pressure, Hb: hemoglobin, WBC: white blood cells, AR: alkaline reserves, ASAT: aspartate aminotransferase, ALAT: alanine aminotransferase, GGT: gamma glutamyl transferase, CPK: creatine phosphokinase, AP: alkaline phosphatase, LDH: lactate dehydrogenase, CRP: Creactive protein, SA: serum albumin. 
Drugs involved were blockers of renin-angiotensin system (BRAS) (35\%), aminoglycosides (16\%), non-steroidal anti-inflammatory drugs (NSAIDs) (16\%), diuretics (13\%), lipid-lowering agents (10\%), rifampicin (6\%) and ifosfamide (3\%) (Table 2).

Intercurrent factor to drug intake was identified in 16 cases (52\%). We found extracellular dehydration in nine cases (29\%) and infectious episode in seven cases (23\%). Main drug combinations were with diuretics in 16 cases (52\%) and with angiotensin converting enzyme inhibitor (ACEi) or angiotensin receptor blockers (ARB) in eight cases (26\%) (Table 3). Gentamicin was associated with an ACEi or ARB and a diuretic (furosemide) in two cases. NSAIDs were associated with a diuretic (furosemide) and an $\mathrm{ARB}$ in one case.

Oligo anuria was observed in 5 cases (16\%). Proteinuria with urine strips was noted in 25 cases (81\%) with hematuria in seven cases (22\%).

Median maximum serum creatinine reached was $631.52 \mu \mathrm{mol} / \mathrm{L}(157-1198 \mu \mathrm{mol} / \mathrm{L})$. AKI was grade 3 in 24 cases (77\%), grade 2 in three cases (10\%) and grade 1 in four cases (13\%). Hyperkalemia was noted in 6 cases (19.5\%). Metabolic acidosis was present

Table 2. Type and dose of drugs.

\begin{tabular}{ccccc}
\hline Offending drug & $\begin{array}{c}\text { Average dose } \\
(\mathrm{mg} / \text { day })\end{array}$ & $\begin{array}{c}\text { Average } \\
\text { duration (days) }\end{array}$ & $\begin{array}{c}\text { Number of } \\
\text { patients }\end{array}$ & Percentage (\%) \\
\hline Gentamicin & 160 & 7 & 5 & 16 \\
ACEi & 22 & 60 & 7 & 23 \\
ARB & 187 & 30 & 3 & 10 \\
ARB + hydrochlorothiazide & $160 / 25$ & 10 & 1 & 3 \\
Furosemide & 250 & - & 1 & 3 \\
Triamterene + Methyclothiazide & $150 / 5$ & - & 3 & 10 \\
Rifampicin & 450 & 8.5 & 2 & 6 \\
Statin & 20 & - & 2 & 6 \\
Fibrate & 200 & - & 1 & 3 \\
NSAIDs & 100 & 5 & 5 & 16 \\
Ifosfamide & 10,000 & 3 & 1 & 3 \\
\hline
\end{tabular}

ACEi: angiotensin converting enzyme inhibitor, ARB: angiotensin receptor blockers, NSAIDs: non-steroidal anti-inflammatory drugs.

Table 3. Combination of drugs in our study.

\begin{tabular}{ccc}
\hline Drug & + ACEi/ARB & + Furosemide \\
\hline Gentamicin & $2(6 \%)$ & $3(10 \%)$ \\
NSAIDs & $3(10 \%)$ & $2(6 \%)$ \\
ACEi/ARB & - & $8(26 \%)$ \\
Triamterene + Methyclothiazide & $3(10 \%)$ & - \\
\hline
\end{tabular}

NSAIDs: non-steroidal anti-inflammatory drugs, ACEi: angiotensin converting enzyme inhibitor, ARB: angiotensin receptor blockers. 
in 11 cases $(35 \%)$ with lactic acidosis in one case that was under metformin. Elevated liver enzymes were noted in five cases (16\%). Among these patients, three were under lipid lowering treatment and the others under rifampicin.

Rhabdomylosis was noted in two cases under lipid lowering treatment. Aseptic leukocyturia was observed in four cases (13\%).

Renal ultrasound was made in 26 cases (84\%) and has not found stenosis of renal artery in all cases.

AKI was probably prerenal in 20 cases (65\%), due to acute tubular necrosis in seven cases $(23 \%)$, by acute immunoallergic interstitial nephropathy in two cases (6\%) and by rhamdomyolysis in two cases (6\%).

Kidney biopsy was performed in one case presenting acute tubular necrosis after taking chemotherapy for cutaneous sarcoma without renal recovery after the usual time. It confirmed diagnosis of acute tubular necrosis with chronic interstitial nephritis associated with diabetic glomerulosclerosis.

Offending drug has been stopped in all cases. Oral antidiabetics were stopped when taken and insulin was prescribed in 28 cases (90\%). Rehydration was conducted in 19 cases $(61 \%)$. That was oral in 7 cases $(23 \%)$ and intravenous in 12 cases $(42 \%)$.

Hemodialysis was needed in 13 cases $(42 \%)$.

Complete recovery was noted in 11 cases (35\%) after a median period of 12.18 days [7 - 23 days]. Partial recovery was observed in 16 cases (52\%) and dialysis dependence in two cases (6\%). Evolution depending on the offending drug is summarized in Table 4.

Median follow up time was 25.5 months [2 days - 102 months]. Six patients (12\%) reached finally ESKD after median period of 14.5 months [4 - 24 months].

Death occurred in three cases. Causes of death were hyperkalemia in one case and septic shock in two cases.

Renal survival at 102 months was 57\%. To identify renal prognostic factors we made comparison between patients with complete recovery of renal function with the others (Table 5). Identified renal prognosis factors were then serum phosphorus $>1.47 \mathrm{mmol} / 1$ $(\mathrm{p}=0.01)$, proteinuria at urine strips $(\mathrm{p}=0.042)$, dehydration $(\mathrm{p}=0.013)$, oral antidiabetic treatment $(\mathrm{p}=0.038)$, intravenous rehydration $(\mathrm{p}=0.021)$ and insulin $(\mathrm{p}=$ 0.006).

\section{Discussion}

Drug induced AKI represents $20 \%$ of all etiologies of AKI [10]. Its incidence is increasing due to the emergence of new potentially nephrotoxic molecules and growing drug prescription. Pathophysiologic mechanism of drug-induced nephro toxicity is complex depending on type of drug involved [10]. This is a serious event that is associated with increased morbidity and mortality [9].

Preventive measures require mainly understanding patients and drug-related risk factors. Diabetes which is currently expanding in the world is a major predisposing factor [11] [12].

Our study focused on clinical aspects of drug induced AKI in diabetic patients. 
Table 4. Prognostic factors of drug-induced acute kidney injury.

\begin{tabular}{|c|c|c|c|}
\hline Parameter & Group 1 & Group 2 & $\mathrm{p}$ \\
\hline Age \pm SD (years) & $69.45 \pm 6.876$ & $63.20 \pm 10.144$ & 0.079 (NS) \\
\hline gender $(M / F)$ & 0.37 & 1.5 & 3.04 (NS) \\
\hline $\begin{array}{l}\text { Duration of diabetes } \pm \text { SD } \\
\text { (months) }\end{array}$ & $163.82 \pm 105.574$ & $166.35 \pm 128.882$ & 0.956 (NS) \\
\hline Initial creatinin $\pm S D(\mu \mathrm{mol} / \mathrm{l})$ & $205.00 \pm 138.399$ & $205.76 \pm 127.439$ & 0.988 (NS) \\
\hline $\begin{array}{l}\mathrm{Cl} \text { creat CKD-EPI } \pm \mathrm{SD} \\
\left(\mathrm{ml} / \mathrm{min} / 1.73 \mathrm{~m}^{2}\right)\end{array}$ & $36.590 \pm 24.5463$ & $40.947 \pm 23.8722$ & 0.654 (NS) \\
\hline $\mathrm{BMI} \pm \mathrm{SD}\left(\mathrm{kg} / \mathrm{m}^{2}\right)$ & $26.4943 \pm 5.51768$ & $27.8482 \pm 3.93298$ & $0.502(\mathrm{NS})$ \\
\hline $\mathrm{SBP} \pm \mathrm{SD}(\mathrm{mmhg})$ & $121.82 \pm 35.726$ & $140.00 \pm 21.764$ & 0.088 (NS) \\
\hline $\mathrm{DBP} \pm \mathrm{SD}(\mathrm{mmhg})$ & $68.18 \pm 16.011$ & $77.00 \pm 13.416$ & 0.113 (NS) \\
\hline Proteinuria (dip stiks) & $5(16 \%)$ & $16(52 \%)$ & 0.042 \\
\hline HT & $10(32 \%)$ & $15(48 \%)$ & 1.114 (NS) \\
\hline P TTT oral AD & $7(22 \%)$ & $12(39 \%)$ & 0.038 \\
\hline $\mathrm{DR}$ & $5(16 \%)$ & $10(32 \%)$ & 0.059 (NS) \\
\hline DN & $8(26 \%)$ & $10(32 \%)$ & 1.457 (NS) \\
\hline PVD & $2(6 \%)$ & $1(3 \%)$ & 1.365 (NS) \\
\hline Coronary Disease & $3(10 \%)$ & $3(10 \%)$ & $0.663(\mathrm{NS})$ \\
\hline Associated diuretic & $6(19 \%)$ & $10(32 \%)$ & 0.059 (NS) \\
\hline Associated ACEi & $2(6 \%)$ & $6(19 \%)$ & 0.501 (NS) \\
\hline Dehydratation & $7(22 \%)$ & $3(10 \%)$ & 0.013 \\
\hline Infection & $2(6 \%)$ & $6(19 \%)$ & 0.618 (NS) \\
\hline TTT:insulin & $10(32 \%)$ & $18(58 \%)$ & 0.006 \\
\hline TTT:IV rehydratation & $8(26 \%)$ & $5(16 \%)$ & 0.021 \\
\hline Need to dialysis & $3(10 \%)$ & $10(32 \%)$ & 1.457 (NS) \\
\hline Urea \pm SD $(\mathrm{mmol} / \mathrm{l})$ & $28.914 \pm 14.4125$ & $34.526 \pm 11.6163$ & 0.315 (NS) \\
\hline Creatinine \pm SD $(\mu \mathrm{mol} / \mathrm{l})$ & $567.27 \pm 253.568$ & $666.85 \pm 277.771$ & 0.333 (NS) \\
\hline Uricemia \pm SD $(\mu \mathrm{mol} / 1)$ & $546.00 \pm 150.408$ & $602.79 \pm 228.637$ & 0.519 (NS) \\
\hline Natremia \pm SD $(\mathrm{mmol} / \mathrm{l})$ & $131.56 \pm 6.023$ & $134.05 \pm 6.510$ & 0.341 (NS) \\
\hline Kalemia \pm SD $(\mathrm{mmol} / \mathrm{l})$ & $4.773 \pm 1.3222$ & $4.630 \pm 1.3095$ & 0.774 (NS) \\
\hline Serum chloride \pm SD $(\mathrm{mmol} / \mathrm{l})$ & $95.64 \pm 9.277$ & $95.87 \pm 6.937$ & 0.943 (NS) \\
\hline $\mathrm{AR} \pm \mathrm{SD}(\mathrm{mmol} / \mathrm{l})$ & $18.738 \pm 5.6778$ & $18.618 \pm 6.4346$ & 0.967 (NS) \\
\hline calcemia $\pm \mathrm{SD}(\mathrm{mmol} / \mathrm{l})$ & $2.3310 \pm 0.17960$ & $2.2120 \pm 0.25549$ & 0.215 (NS) \\
\hline Phosphatemia \pm SD (mmol/l) & $1.3200 \pm 0.59353$ & $2.0713 \pm 0.75124$ & 0.01 \\
\hline $\mathrm{Hb} \pm \mathrm{SD}(\mathrm{g} / \mathrm{dl})$ & $9.618 \pm 1.7904$ & $9.805 \pm 1.2412$ & 0.735 (NS) \\
\hline $\mathrm{CRP} \pm \mathrm{SD}(\mathrm{mg} / \mathrm{l})$ & $33.082 \pm 55.5428$ & $23.150 \pm 39.6787$ & 0.624 (NS) \\
\hline $\mathrm{SA} \pm \mathrm{SD}(\mathrm{g} / \mathrm{l})$ & $34.210 \pm 7.8614$ & $30.720 \pm 6.1603$ & 0.226 (NS) \\
\hline Glycemia $\pm \mathrm{SD}(\mathrm{mmol} / \mathrm{l})$ & $9.080 \pm 5.1270$ & $8.470 \pm 3.0653$ & 0.680 (NS) \\
\hline 24-hour Proteinuria \pm SD $(\mathrm{g} / \mathrm{l})$ & $0.8656 \pm 1.14212$ & $1.7560 \pm 2.24910$ & 0.136 (NS) \\
\hline
\end{tabular}

Group 1: patients with complete recovery of renal function, group 2: all the other patients, SD: standard deviation, NS: non-significant value, CL creatinine: clearance of creatinine, BMI: body mass index, SBP: systolic blood pressure, DBP: diastolic blood pressure, HT: hypertension, P TTT: previous treatment, AD: antidiabetic, DR: diabetic retinopathy, DN: diabetic neuropathy, PVD: Peripheral vascular disease, ACEi: angiotensin converting enzyme inhibitor, TTT: treatment, IV: intravenous, Hb: hemoglobin, AR: alkaline reserves, SA: serum albumin, CRP: C-reactive protein. 
Table 5. Evolution of patients depending on the drug type.

\begin{tabular}{cccccc}
\hline Drug & $\begin{array}{c}\text { Mean Previous Cl } \\
\text { Creat (ml/min) }\end{array}$ & CR & PR & $\begin{array}{c}\text { Stabilization } \\
\text { Of GFR }\end{array}$ & $\begin{array}{c}\text { Dependance } \\
\text { to dialysis }\end{array}$ \\
\hline Number & & 11 & 16 & 2 & 2 \\
Percentage (\%) & & 35 & 52 & 6 & 6 \\
Gentamicin & 54.14 & 1 & 4 & - & - \\
NSAIDs & 47.5 & 3 & 2 & - & 1 \\
ACEi/ARB & 33.33 & 5 & 3 & 2 & - \\
Statin/fibrate & 27.8 & 1 & 2 & - & - \\
Diuretic & 46 & 1 & 3 & - & - \\
Rifampicin & 72.35 & - & 2 & - & 1 \\
Ifosfamide & 75 & - & - & - & - \\
\hline
\end{tabular}

Cl Creat: clairance creatinine, CR: complete recovery, PR: partial recovery, GFR: glomerular filtration rate, NSAIDs: non-steroidal anti-inflammatory drugs, ACEi: angiotensin converting enzyme inhibitor, ARB: angiotensin receptor blockers

Among risk factors known over literature, our population was mainly female and aged over 65 years with a preexistant renal failure in $74 \%$ of cases. Hypovolemia was present in $29 \%$ of cases.

Indeed, some patient characteristics can predispose to drug-induced nephrotoxicity. Older age and female gender are associated with reduced muscle mass and lower total body water which can impact on drug dose [13] [14]. Risk of drug nephrotoxicity is increased in the patient with CKD. Patient who is on diuretic therapy or has vomiting resulting in extracellular volume depletion is vulnerable also to toxic drug effects on the kidney [13].

BRAS were main causes of AKI in our study. AKI due to BRAS is increasing due to their large use in diabetics to slow progression of diabetic nephropathy. Furthermore, there are actually many evidence based indications for use of these molecules and several guidelines recommend their use for a number of chronic conditions like hypertension or CKD with proteinuria [15].

Our findings are consistent with other studies which have demonstrated an increasing incidence of AKI from treatment with BRAS. There is usually presence of an intercurrent illness and it is more common in patients with known renal failure [15]. We found in our study an intercurrent factor in $52 \%$ of all cases.

AKI due to BRAS has been described primarily in patients with bilateral renal artery stenosis or with a single kidney and unilateral stenosis, and in some conditions like severe congestive heart failure and concomitant diuretic therapy [16]. In our cases, renal ultrasound excluded renal artery stenosis but concomitant use of diuretics was present in $26 \%$ of all cases. Discontinuation of BRAS leads generally to recovery of renal function meanwhile exceptions has been reported [16].

Aminoglycosides and NSAIDs were either frequently observed in our study. Aminoglycosides are typically the most common drugs involved in the literature [17]. They 
are responsible for about $25 \%$ of AKI [18]. In our study, they were found in $16 \%$ of cases. That was gentamicin in all reported cases.

The inhibition of prostaglandin synthesis by NSAIDs causes a reduction in renal blood flow and glomerular filtration [19]. It is essentially in some pathological situations where renin-angiotensin system is strongly stimulated that the effect of NSAIDs promotes the onset of AKI. Then combination of BRAS with NSAIDs should be avoided especially in pre-existing renal insufficiency or extracellular volume depletion.

Lipid-lowering agents may lead to AKI via rhabdomyolysis [20]. This risk is particularly increased in elderly diabetics. We reported two cases of rhabdomyolysis.

The other drugs found in our study were diuretics, rifampicin and cancer chemotherapy. Antituberculosis agents can induce AKI by immunoallergic mechanism [21] [22]. Hepatonephritis due to rifampicin was found in two cases in our study.

The presence of diabetes poses certain particular problems in the management of AKI. Rapid institution of dialysis is important as the diabetic patient may tolerate uraemia less well [11].

Diabetes must be well controlled as uncontrolled ketosis may worsen hyperkalemia and metabolic acidosis, with increased risk of adverse effects of antidiabetic treatment. Indeed, we reported one case of lactic acidosis in our study due to the use of metfor$\min$.

Patients with diabetes are then at increased risk of developing AKI [23]. This condition carries a high mortality and management may be more complicated by the presence of diabetes. Some cases may be avoidable by reducing exposure of the diabetic patient to nephrotoxic agents.

Preventive measures are essential by assessing baseline renal function before initiation of therapy, adjusting the drug dosage and avoiding use of nephrotoxic drug combinations [5].

Non-recovery or incomplete recovery of renal function can translate into a need for long-term dialysis which is associated with low quality of life and representing a major burden for healthcare systems [24] [25].

Presence of factors such as elevated serum phosphorus, dehydration and proteinuria were associated with a poor prognosis in our study.

It is now well established that proteinuria is a progression factor of CKD. The degree of proteinuria is one of the most important predictors of progression of kidney disease, as well as the response to antiproteinuric treatment in almost all studies on CKD.

Dehydration and intravenous rehydration were identified as prognostic factors in our study.

Indeed, improvement of the hemodynamic status of patient with AKI and especially perfusion pressure has a beneficial effect on kidney function and helps to minimize the effect of further attacks on the already injured kidney.

AKI increases the risk of progression to advanced CKD in patients with diabetes regardless of the major risk factors for progression of CKD and each episode of AKI dual this risk. These data suggest that even moderate AKI in diabetics with preserved renal 
function should be considered as a serious event [25] [26].

Our study has some limitation such as the retrospective nature of the study and the number of patients included quite low given the frequency of this condition. It is probably underestimated in our study due to the selection criteria we adopted since we included only hospitalized patients.

\section{Conclusions}

Drug-induced AKI is potentially serious in diabetics due to the high risk of progression to ESKD, especially in case of pre-existing renal insufficiency.

Prevention is so crucial. The measures consist mainly in determination of baseline renal function before initiation of treatment, with adjustment of drug dosage. Prescription of potentially nephrotoxic drugs should be carried out in strict compliance with therapeutic indications. It must take into account drug interactions and patients related risk factors. Correction of intravascular depletion to maintain renal perfusion before initiation of nephrotoxic agents is also essential.

\section{Declaration of interest:}

The authors report no conflicts of interest. The authors alone are responsible for the content and writing of the paper.

\section{Ethical Approval}

All procedures performed in our study were in accordance with the ethical standards of the institutional and/or national research committee and with the 1964 Helsinki declaration.

\section{References}

[1] Blix, H.S., Viktil, K.K., Moger, T.A. and Reikvam, A. (2006) Use of Renal Risk Drugs in Hospitalized Patients with Impaired Renal Function-An Underestimated Problem? Nephrology Dialysis Transplantation, 21, 3164-3171. http://dx.doi.org/10.1093/ndt/gfl399

[2] Perazella, M.A. (2009) Renal Vulnerability to Drug Toxicity. Clinical Journal of the American Society of Nephrology, 4, 1275-1283. http://dx.doi.org/10.2215/CJN.02050309

[3] Thatte, L. and Vaamonde, C.A. (1996) Drug-Induced Nephrotoxicity: The Crucial Role of Risk Factors. Postgraduate Medicine, 100, 83-84. http://dx.doi.org/10.3810/pgm.1996.12.128

[4] Aitken, E., Carruthers, C., Gall, I., Kerr, I., Geddes, C. and Kingsmore, D. (2013) Acute Kidney Injury: Outcomes and Quality of Care. Q J M: An International Journal of Medicine, 106, 323-332. http://dx.doi.org/10.1093/qjmed/hcs237

[5] Kleinknecht, D., Landais, P. and Goldfarb, B. (1987) Drug-Associated Acute Renal Failure: A Prospective Collaborative Study of 81 Biopsied Patients. Advances in Experimental Medicine and Biology, 212, 125-128.

[6] Thakar, C.V., Christianson, A., Himmelfarb, J. and Leonard, A.C. (2011) Acute Kidney Injury Episodes and Chronic Kidney Disease Risk in Diabetes Mellitus. Clinical Journal of the American Society of Nephrology, 6, 2567-2572. http://dx.doi.org/10.2215/CJN.01120211

[7] Kidney Disease: Improving Global Outcomes (KDIGO) CKD Working Group. KDIGO 
Clinical Practice Guideline for Acute Kidney Injury. Kidney International Supplements, 2, 1-141.

[8] Kidney Disease: Improving Global Outcomes (KDIGO) CKD Working Group. KDIGO 2012 Clinical Practice Guideline for the Evaluation and Management of Chronic Kidney Disease. Kidney International Supplements, 3, 1-150.

[9] Bagshaw, S.M. (2006) The Long-Term Outcome after Acute Renal Failure. Current Opinion in Critical Care, 12, 561-566. http://dx.doi.org/10.1097/01.ccx.0000247445.71381.72

[10] Taber, S.S. and Pasko, D.A. (2008) The Epidemiology of Drug-Induced Disorders: The Kidney. Expert Opinion on Drug Safety, 7, 679-690. http://dx.doi.org/10.1517/14740330802410462

[11] Woodrow, G., Brownjohn, A.M. and Turney, J.H. (1994) Acute Renal Failure in Patients with Type 1 Diabetes Mellitus. Postgraduate Medical Journal, 70, 192-194.

http://dx.doi.org/10.1136/pgmj.70.821.192

[12] Girman, C.J., Kou, T.D., Brodovicz, K., Alexander, C.M., O’Neill, E.A., Engel, S., et al. (2012) Risk of Acute Renal Failure in Patients with Type 2 Diabetes Mellitus. Diabetic Medicine, 29, 614-621. http://dx.doi.org/10.1111/j.1464-5491.2011.03498.x

[13] Pazhayattil, G.S. and Shirali, A.C. (2014) Drug-Induced Impairment of Renal Function. International Journal of Nephrology and Renovascular Disease, 7, 457-468.

[14] Coca, S.G., Cho, K.C. and Hsu, C.Y. (2011) Acute Kidney Injury in the Elderly: Predisposition to Chronic Kidney Disease and Vice Versa. Nephron Clinical Practice, 119, c19-c24. http://dx.doi.org/10.1159/000328023

[15] Tomlinson, L.A., Abel, G.A., Chaudhry, A.N., Tomson, C.R., et al. (2013) ACE Inhibitor and Angiotensin Receptor-II Antagonist Prescribing and Hospital Admissions with Acute Kidney Injury: A Longitudinal Ecological Study. PLoS ONE, 8, e78465. http://dx.doi.org/10.1371/journal.pone.0078465

[16] Albareda, M.M and Corcoy, R. (1998) Reversible Impairment of Renal Function Associated with Enalapril in a Diabetic Patient. CMAJ, 159, 1279-1281.

[17] Swan, S.K. (1997) Aminoglycoside Nephrotoxicity. Seminars in Nephrology, 17, 27-33.

[18] Alexandridis, G., Liberopoulos, E. and Elisaf, M. (2003) Aminoglycoside-Induced Reversible Tubular Dysfunction. Pharmacology, 67, 118-120. http://dx.doi.org/10.1159/000067797

[19] Perez Gutthann, S., Garcia Rodriguez, L.A., Raiford, D.S., Duque Oliart, A. and Ris Romeu, J. (1996) Nonsteroidal Anti-Inflammatory Drugs and the Risk of Hospitalization for Acute Renal Failure. Archives of Internal Medicine, 156, 2433-2439. http://dx.doi.org/10.1001/archinte.156.21.2433

[20] Graham, D.J., Staffa, J.A., Shatin, D., et al. (2004) Incidence of Hospitalized Rhabdomyolysis in Patients Treated with Lipid-Lowering Drugs. JAMA, 292, 2585-2590. http://dx.doi.org/10.1001/jama.292.21.2585

[21] Gabow, P.A., Lacher, J.W. and Neff, T.A. (1976) Tubulo-Interstitial and Glomerular Nephritis Associated with Rifampin. Report of a Case. JAMA, 235, 2517-2518. http://dx.doi.org/10.1001/jama.1976.03260490035017

[22] Muthukumar, T., Jayakumar, M., Fernando, E.M. and Muthusethupathi, M.A. (2002) Acute Renal Failure due to Rifampicin: A Study of 25 Patients. American Journal of Kidney Diseases, 40, 690-696. http://dx.doi.org/10.1053/ajkd.2002.35675

[23] James, M.T., Grams, M.E., Woodward, M., Elley, C.R., Green, J.A., Wheeler, D.C., et al. (2015) A Meta-Analysis of the Association of Estimated GFR, Albuminuria, Diabetes Mellitus, and Hypertension with AKI. American Journal of Kidney Diseases, 66, 602-612. http://dx.doi.org/10.1053/j.ajkd.2015.02.338 
[24] Coca, S.G., Singanamala, S. and Parikh, C.R. (2012) Chronic Kidney Disease after Acute Kidney Injury: A Systematic Review and Meta-Analysis. Kidney International, 81, 442-448. http://dx.doi.org/10.1038/ki.2011.379

[25] Jones, J., Holmen, J., De Graauw, J., et al. (2012) Association of Complete Recovery from Acute Kidney Injury with Incident CKD Stage 3 and All Cause Mortality. American Journal of Kidney Diseases, 60, 402-408. http://dx.doi.org/10.1053/j.ajkd.2012.03.014

[26] Hsu, C.Y., Chertow, G.M., McCulloch, C.E., Fan, D., Ordonez, J.D. and Go, A.S. (2009) Nonrecovery of Kidney Function and Death after Acute or Chronic Renal Failure. Clinical Journal of the American Society of Nephrology, 4, 891-898.

http://dx.doi.org/10.2215/CJN.05571008

Submit or recommend next manuscript to SCIRP and we will provide best service for you:

Accepting pre-submission inquiries through Email, Facebook, LinkedIn, Twitter, etc. A wide selection of journals (inclusive of 9 subjects, more than 200 journals)

Providing 24-hour high-quality service

User-friendly online submission system

Fair and swift peer-review system

Efficient typesetting and proofreading procedure

Display of the result of downloads and visits, as well as the number of cited articles

Maximum dissemination of your research work

Submit your manuscript at: http://papersubmission.scirp.org/

Or contact ojneph@scirp.org 